\title{
Genetic analyses of blood $\beta$-hydroxybutyrate predicted from milk infrared spectra and its association with longevity and female reproductive traits in Holstein cattle
}

\author{
W. Lou, ${ }^{1} \oplus$ H. Zhang, ${ }^{1} \oplus$ H. Luo, ${ }^{1} \odot$ Z. Chen, ${ }^{1}$ R. Shi, ${ }^{1,2} \odot$ X. Guo, ${ }^{3} \odot$ Y. Zou, ${ }^{4} \odot$ L. Liu,,${ }^{4}$ L. F. Brito, ${ }^{5} \odot$ G. Guo, ${ }^{6} \odot$ \\ and Y. Wang ${ }^{1 *}$ (i) \\ ${ }^{1}$ National Engineering Laboratory of Animal Breeding; Key Laboratory of Animal Genetics, Breeding and Reproduction, \\ Ministry of Agriculture and Rural Affairs (MARA); College of Animal Science and Technology, China Agricultural University, Beijing, 100193, China \\ ${ }^{2}$ Animal Breeding and Genomics Group, Wageningen University \& Research, PO Box 338, 6700 AH Wageningen, the Netherlands \\ ${ }^{3}$ Center of Quantitative Genetics and Genomics, Aarhus University, Tjele, 8830, Denmark \\ ${ }^{4}$ Beijing Dairy Cattle Center, Beijing, 100192, China \\ ${ }^{5}$ Department of Animal Science, Purdue University, West Lafayette, IN 47907 \\ ${ }^{6}$ Beijing Sunlon Livestock Development Company Limited, Beijing, 10029, China
}

\section{ABSTRACT}

Ketosis is one of the most prevalent and complex metabolic disorders in high-producing dairy cows and usually detected through analyses of $\beta$-hydroxybutyrate (BHB) concentration in blood. Our main objectives were to evaluate genetic parameters for blood BHB predicted based on Fourier-transform mid-infrared spectra from 5 to $305 \mathrm{~d}$ in milk, and estimate the genetic relationships of blood BHB with 7 reproduction traits and 6 longevity traits in Holstein cattle. Predicted blood BHB records of 11,609 Holstein cows (after quality control) were collected from 2016 to 2019 and used to derive 4 traits based on parity number, including predicted blood BHB in all parities (BHBp), parity 1 (BHB1), parity 2 (BHB2), and parity $3+$ (BHB3). Single- and multitrait repeatability models were used for estimating genetic parameters for the 4 BHB traits. Random regression test-day models implemented via Bayesian inference were used to evaluate the daily genetic feature of BHB variability. In addition, genetic correlations were calculated for the 4 BHB traits with reproduction and longevity traits. The heritability estimates of BHBp, BHB1, BHB2, and BHB3 ranged from $0.100 \pm$ 0.026 ( \pm standard error) to $0.131 \pm 0.023$. The BHB in parities 1 to $3+$ were highly genetically correlated and ranged from 0.788 (BHB1 and BHB2) to 0.911 (BHB1 and BHB3). The daily heritability of BHBp ranged from 0.069 to 0.195 , higher for the early and lower for the later lactation periods. A similar trend was observed for BHB1, BHB2, and BHB3. There are low direct genetic correlations between BHBp and selected

Received March 2, 2021

Accepted November 16, 2021.

*Corresponding author: wangyachun@cau.edu.cn reproductive performance and longevity traits, which ranged from $-0.168 \pm 0.019$ (BHBp and production life) to $0.157 \pm 0.019$ (BHBp and age at first calving) for the early lactation stage $(5$ to $65 \mathrm{~d})$. These direct genetic correlations indicate that cows with higher BHBp (greater likelihood of having ketosis) in blood usually have shorter production life $(-0.168 \pm 0.019)$. Cows with higher fertility and postpartum recovery, such as younger age at first calving $(0.157 \pm 0.019)$ and shorter interval from calving to first insemination in heifer $(0.111 \pm 0.006)$, usually have lower BHB concentration in the blood. Furthermore, the direct genetic correlations change across parity and lactation stage. In general, our results suggest that selection for lower predicted BHB in early lactation could be an efficient strategy for reducing the incidence of ketosis as well as indirectly improving reproductive and longevity performance in Holstein cattle.

Key words: $\beta$-hydroxybutyrate, Chinese Holstein, metabolic disease, random regression model

\section{INTRODUCTION}

Ketosis, also known as hyperketonemia and ketonemia, is one of the most frequent metabolic diseases caused by an energy metabolism disorder in postpartum dairy cows (Overton et al., 2017; Benedet et al., 2019). For instance, the prevalence rate of subclinical ketosis in Holstein cows in 10 European countries ranged from $11.2 \%$ to $36.6 \%$, with an average of $21.8 \%$ (Suthar et al., 2013). The median incidence of clinical ketosis in Holstein cows was $3.1 \%$ based on 11 studies (Pryce et al., 2016). Previous reports indicated that the within-herd incidence of postpartum hyperketonemia in dairy cows ranges from $23 \%$ to $60 \%$ (McArt et al., 2013a; Mahrt et al., 2015; Vanholder et al., 2015). Such 
high incidence of ketosis not only affects welfare, milk yield and composition, and reproductive performance in current parity, but can also considerably affect the future performance of dairy cows (McArt et al., 2013b; Raboisson et al., 2014; Mostert et al., 2018). In Canadian dairy cattle, every $1 \%$ increase in the incidence of subclinical ketosis has been estimated to cause an economic loss of $\$ 0.015$ per cow per day (McLaren et al., 2006), and reproductive failure was the main component responsible for these losses $(\sim 34 \%$; McArt et al., 2015). Thus, the negative effect of ketosis on the reproductive performance of dairy cattle needs to be further investigated for defining more effective mitigation strategies.

As the main pathological mechanism of ketosis, insufficient adaptation of an individual's metabolism can result in negative energy balance (NEB), which leads to excessive body fat mobilization (Esposito et al., 2014). Therefore, high concentrations of nonesterified fatty acids and ketones including BHB, acetone, and acetoacetate appear in the blood, milk, and other body environments (Herdt, 2000). $\beta$-Hydroxybutyrate is the major and most stable circulating ketone in body fluids; accordingly, the concentration of BHB is generally used as a reference for ketosis, and BHB can more precisely represent the biological variation in susceptibility than other ketone bodies (Duffield et al., 2009; van der Drift et al., 2012a; Denis-Robichaud et al., 2014). Nonetheless, the cost of common methods, such as commercially available kits (Leroy et al., 2004), makes it difficult to regularly test all the herd cows at risk. A BHB detection program based on routine milk analysis may be a more practical and less labor-intensive approach (Pralle et al., 2018). In this context, BHB in blood or milk can be accurately predicted through analysis of Fourier-transform mid-infrared (FT-MIR) spectra of milk with low cost and high throughput (Heuer et al., 2001; van Knegsel et al., 2010; Grelet et al., 2016). The BHB-predicted phenotypes provide an opportunity to implement genetic and genomic selection for lower ketosis incidence in dairy cattle.

Reproductive performance traits are key functional traits as they directly affect productive efficiency in the dairy industry (Lucy, 2001; Stevenson and Britt, 2017). The relationship between ketosis and reproductive performance was first reported in Swedish dairy cattle (Andersson et al., 1991). In general, there is a negative phenotypic correlation between the concentration of BHB in the blood and pregnancy rate at the first service (Walsh et al., 2007). Furthermore, uterine diseases and delayed luteal activity have been associated with elevated BHB concentrations (Reist et al., 2003; Hammon et al., 2006). Many of these reproductive disorders in high-producing dairy cows often result from metabolic diseases (Dobson et al., 2007; Sheldon et al., 2008). Poor reproductive and health performance often leads to premature culling and decreased life span of dairy cows (Oltenacu and Broom, 2010). Therefore, the genetic relationship of $\mathrm{BHB}$ with female reproductive performance and longevity is of great importance. To our best knowledge, most studies reported genetic parameters of BHB in milk or blood using linear animal models and explored the relationships of BHB with metabolic diseases, energy balance, and milk production in different populations such as Greek (Oikonomou et al., 2008), Canadian (Koeck et al., 2014, 2016), and Dutch (van der Drift et al., 2012b) Holsteins, and Norwegian Red cattle (Belay et al., 2017). However, the genetic relationships for $\mathrm{BHB}$ with reproduction and longevity traits in dairy cattle have not yet been thoroughly investigated. Therefore, this study aimed to (1) estimate genetic parameters for predicted blood BHB using both random regression test-day models through Bayesian inference and linear repeatability models, and (2) calculate the genetic correlations of blood BHB traits with reproductive performance and longevity indicators in Holstein cattle.

\section{MATERIALS AND METHODS}

\section{Ethics Committee Approval}

The data used in this study were collected in strict adherence to the protocol approved by the Animal Welfare Committee of the China Agricultural University, Beijing, China (protocol number: DK996).

\section{Data Sets}

Test-day predicted blood BHB (BHBp) records from 12,157 Holstein cows were obtained from December 2016 to March 2019 in 12 dairy farms located in Beijing, China. The freestall barn system and TMR were used in all herds and the average numbers of cows and records per herd were $967 \pm 595$ and $2,861 \pm 2,636$, respectively. The average test-day milk yield per cow is about $35 \pm 9 \mathrm{~kg}$. Individual milk samples were tested monthly at the Beijing Dairy Cattle Center (Beijing, China), and the pedigree data were also provided. Blood BHB (mmol/L) was predicted from milk spectra data via internal inbuilt modules in FTS machines (Bentley Instruments Inc.).

The 7 reproduction traits (measured in $\sim 140,000$ cows) and 6 longevity-indicator traits (measured in $\sim 130,000$ cows) were provided by the Independent Innovation League of Dairy Breeding (Beijing, China). The reproduction traits included age at first calving in heifers (AFC, d), age at first insemination in heifers 
(AFS, d), interval from calving to first insemination in first-parity (ICF1, d) and multiparous (ICF2, d) cows, interval from first to last insemination for firstparity (IFLC1, d) and multiparous (IFLC2, d) cows, and interval from first to last insemination of heifers (IFLH, d). Additional details about the definition of the reproductive performance traits can be found in Guo et al. (2014) and Liu et al. (2017). Furthermore, 6 longevity-indicator traits included the period from the first calving to the end of the first (LS1, d), second (LS2, d), third (LS3, d), fourth (LS4, d), and fifth (LS5, d) parity, and productive life $(\mathbf{P L}, \mathrm{d})$. The trait definitions used for the longevity traits are described in Zhang et al. (2019, 2021). The traits described above were recorded until December 2019. All cows with BHB records were also recorded for the fertility and longevity indicators and additional details about the data sets are shown in Supplemental Table S1 (https://figshare .com/articles/dataset/Supplemental_Table_S1_docx/ 18133721).

Only BHBp records ranging from 0.004 to 4.818 $\mathrm{mmol} / \mathrm{L}$ were kept in the analyses. The records of cows with DIM out of the range from 5 to $305 \mathrm{~d}$ were removed, while 10 DIM stages can be obtained with the interval of $30 \mathrm{~d}$. A total of 34,338 test-day BHBp records from 11,609 Holstein cows were retained in the data set, whereas the concentrations of BHBp in different parities $(1,2$, and $3+)$ were treated as separate traits (BHB1 for first-parity, BHB2 for second parity, and BHB3 for third or greater parity cows) and the numbers of animals were $6,420,4,395$, and 3,925, respectively. In addition, the pedigree used in the genetic analysis was traced back up to 6 generations and included 449,819 animals.

\section{Genetic Analyses of Predicted Blood BHB}

Mixed model analyses were performed using the PROC MIXED procedure implemented in SAS 9.2 (SAS Institute Inc.) with BHBp, BHB1, BHB2, and BHB3 as the dependent variables to identify the systematic effects that should be included in the genetic models. Genetic analyses of BHBp were performed using the AI-REML procedure implemented in the DMU software (Madsen et al., 2006). A linear repeatability model (model 1) was used to estimate the heritability and repeatability for BHB. Model 1 can be described as follows:

$$
\begin{aligned}
& y_{i j k l m}= \\
& \mathrm{HYS}_{i}+P_{j}+\beta_{1} \mathrm{DIM}_{k}+\beta_{2} e_{k}^{-0.05 \mathrm{DIM}}+a_{l}+p e_{l}+\varepsilon_{i j k l m},
\end{aligned}
$$

[model 1] where $y_{i j k l m}$ are the phenotypic records for BHBp, $\mathrm{BHB} 1, \mathrm{BHB} 2$, or BHB3; $\mathrm{HYS}_{i}$ is the fixed effect of the herd-year-season $i$ (71 levels); $P_{j}$ is the fixed effect of parity $j(1,2$, or $3+) ; \mathrm{DIM}_{k}$ and $e_{k}^{-0.05 \mathrm{DIM}}$ are the covariate effects of DIM (interval of 5 to $305 \mathrm{~d}$ ), which modified the lactation curve function (Cobby and Le Du, 1978; Wilmink, 1987; Zaalberg et al., 2019); $\beta_{1}$ and $\beta_{2}$ are the regression coefficients of DIM; $a_{l}$ is the random additive genetic effect; $p e_{l}$ is the random permanent environmental effect; and $\varepsilon_{i j k l m}$ is the random residual effects. It was assumed that $a \sim N\left(\mathbf{0}, \mathbf{A} \sigma_{a}^{2}\right)$, pe $N\left(\mathbf{0}, \mathbf{I} \sigma_{p e}^{2}\right)$, and $\varepsilon \sim N\left(\mathbf{0}, \mathbf{I} \sigma_{e}^{2}\right)$, where $\mathbf{A}$ is the additive pedigree-based relationship matrix, $\sigma_{a}^{2}$ is the additive genetic variance, $\sigma_{p e}^{2}$ is the permanent environment variance, $\sigma_{e}^{2}$ is the random residual variance, and $\mathbf{I}$ is an identity matrix. To investigate the genetic relationships among BHB recorded across parities, a multitrait repeatability model (model 2 ) was fitted and included the same effects as described in model 1.

A single-trait random regression test-day model (model 3) was used to estimate the daily additive genetic variance components, permanent environmental effects, and residual effect for the 4 BHB traits across DIM based on the RJMC module in the DMU software (Madsen et al., 2006). Bayesian methods based on the Gibbs sampler and Markov Chain Monte Carlo (MCMC) algorithm were used to estimate the variance components for all traits. A MCMC chain length of 500,000 cycles, considering a burn-in period of 100,000, and a sampling interval (thin) of 50 cycles were used. The convergence of the chain was assessed using the package "coda" (Plummer et al., 2016) in the R software according to the Geweke (1991) criteria. Model 3 can be described as follows:

$$
\begin{aligned}
& y_{i j l m n o}= \\
& \mathrm{HYS}_{i}+P_{j}+\sum_{\mathrm{n}=0}^{3} \mathrm{DIM}_{n} a_{m n}+\sum_{\mathrm{n}=0}^{3} \mathrm{DIM}_{n} p e_{m n}+\varepsilon_{i j m n o}, \\
& {[\text { model 3] }}
\end{aligned}
$$

where $y_{i j l m n o}$ is the response variable of BHBp, BHB1, $\mathrm{BHB} 2$, or BHB3; $\mathrm{DIM}_{n}$ is the covariate of the $n$th Legendre orthogonal polynomial $(n=0,1,2,3$; Kirkpatrick et al., 1990); $a_{m n}$ and $p e_{m n}$ are the additive genetic and permanent environmental random regression coefficients of DIM, respectively. The continuous time point (DIM) was normalized in the range of -1 to 1 and then converted to different orders of Legendre polynomials. As shown in Supplemental Table S2 (https://figshare .com/articles/dataset/Supplemental_Table_S2_docx/ 18133727), the optimal orthogonal polynomials $(\mathbf{T})$ were added into model 3 . For the random effects, the 
following prior distributions were assumed: $a \sim$ $N(\mathbf{0}, \mathbf{G} \otimes \mathbf{A}), p e \sim N(\mathbf{0}, \mathbf{P} \otimes \mathbf{I})$, and $\varepsilon \sim N\left(\mathbf{0}, \mathbf{I} \sigma_{e}^{2}\right)$, where $\mathbf{G}$ and $\mathbf{P}$ are the covariance matrices associated with the random regression polynomial coefficients for animal additive genetic and permanent environmental effects, respectively. All the other parameters were previously defined. Furthermore, we assumed that $\mathbf{G}$ and $\mathbf{P}$ followed the inverted Wishart (IW) distribution, IW $\left(\mathrm{v}_{\mathrm{G}}, \mathbf{V}_{\mathrm{G}}\right)$, and IW $\left(\mathrm{v}_{\mathrm{PE}}, \mathrm{V}_{\mathrm{PE}}\right)$, where $\mathrm{v}$ is the degrees of freedom $(\mathrm{v}=3)$ and $\mathbf{V}$ is the scale matrix. $\sigma_{e}^{2}$ was assumed to follow a scaled inverted chi-squared distribution.

For model 1 and 2, the heritability and repeatability parameters were defined as $\mathrm{h}^{2}=\frac{\sigma_{a}^{2}}{\sigma_{p}^{2}}$ and $r_{e}=\frac{\sigma_{a}^{2}+\sigma_{p e}^{2}}{\sigma_{p}^{2}}$, respectively, and $\sigma_{p}^{2}=\sigma_{a}^{2}+\sigma_{p e}^{2}+\sigma_{e}^{2}$. The genetic correlation coefficient was calculated as $\mathrm{r}=\frac{\sigma_{i j}}{\sqrt{\sigma_{i}^{2} \sigma_{j}^{2}}}$. The squares of the standard errors (SE) for the heritability and genetic correlation coefficient were calculated according to Su et al. (2007):

$$
\begin{aligned}
& \operatorname{SE}^{2}\left(\mathrm{~h}^{2}\right)=\left[\frac{\hat{\sigma}_{a}^{2}}{\hat{\sigma}_{p}^{2}}\right]^{2}\left[\frac{\operatorname{Var}\left(\hat{\sigma}_{a}^{2}\right)}{\left(\hat{\sigma}_{a}^{2}\right)^{2}}+\frac{\operatorname{Var}\left(\hat{\sigma}_{p}^{2}\right)}{\left(\hat{\sigma}_{p}^{2}\right)^{2}}-2 \frac{\operatorname{Cov}\left(\hat{\sigma}_{a}^{2}, \hat{\sigma}_{p}^{2}\right)}{\hat{\sigma}_{a}^{2} \hat{\sigma}_{p}^{2}}\right], \\
& \mathrm{SE}^{2}(\mathrm{r})=\left[\frac{\hat{\sigma}_{i j}^{2}}{\hat{\sigma}_{i}^{2} \hat{\sigma}_{j}^{2}}\right] \\
& {\left[\frac{\operatorname{Var}\left(\hat{\sigma}_{i j}\right)}{\left(\hat{\sigma}_{i j}\right)^{2}}+\frac{\operatorname{Var}\left(\hat{\sigma}_{i}^{2}\right)}{4\left(\hat{\sigma}_{i}^{2}\right)^{2}}+\frac{\operatorname{Var}\left(\hat{\sigma}_{j}^{2}\right)}{4\left(\hat{\sigma}_{j}^{2}\right)^{2}}\right.} \\
& \left.-\frac{\operatorname{Cov}\left(\hat{\sigma}_{i j}, \hat{\sigma}_{i}^{2}\right)}{\hat{\sigma}_{i j} \hat{\sigma}_{i}^{2}}-\frac{\operatorname{Cov}\left(\hat{\sigma}_{i j}, \hat{\sigma}_{j}^{2}\right)}{\hat{\sigma}_{i j} \hat{\sigma}_{j}^{2}}+\frac{\operatorname{Cov}\left(\hat{\sigma}_{i}^{2}, \hat{\sigma}_{j}^{2}\right)}{2 \hat{\sigma}_{i}^{2} \hat{\sigma}_{j}^{2}}\right]
\end{aligned}
$$

The (co)variances of the estimated parameters $\left(\sigma_{i}^{2}, \sigma_{i j}\right)$ between trait $i$ and trait $j$ are obtained from the inverse of the average information matrix of model 2 .

For model 3, the additive and permanent environmental (co)variances for all DIM were calculated using the posterior mean of the (co)variance components estimated for the random regression coefficients of these effects (i.e., $\boldsymbol{\lambda}=\mathbf{T G T}^{\prime}, \boldsymbol{\xi}=\mathbf{T P T}^{\prime}$ ), where $\boldsymbol{\lambda}$ and $\boldsymbol{\xi}$ are the additive genetic and permanent environmental (co)variance matrices for the DIM, and $\mathbf{T}, \mathbf{G}$, and $\mathbf{P}$ are as previously mentioned. Residual variances were also obtained from the posterior marginal distribution samples. Therefore, the daily variance components and genetic parameters can be calculated. The breeding value for all DIM (5-305 d) of the animal $\mathbf{i}$ were obtained as $\mathbf{E B V}_{\mathbf{i}}=\mathbf{T a}_{\mathbf{i}}$, where $\mathbf{a}_{\mathbf{i}}$ is the vector of breeding values for the regression coefficients of the animal $\mathbf{i}$.

\section{Genetic Correlations for BHB with Reproduction and Longevity Traits}

Genetic correlations and SE of the whole (5-305 d), early (5-65 d), and late (245-305 d) lactations for the 4 BHB traits with reproductive and longevity traits were calculated based on a bivariate animal model. $\beta$-Hydroxybutyrate is a longitudinal trait in each lactation, whereas most of the reproduction and longevity traits are single-measurement traits in each lactation and even in lifetime. Therefore, the adjusted phenotypes for the BHB traits were obtained from model 3 and used as pseudo-phenotypes in the bivariate analyses. For the 7 reproductive traits, the animal models include the fixed effects of herd-year of measurement, calving season, and the random effects of animal additive genetic effect and residual effect. The fixed effects (age at first calving, herd-year of birth, and birth season) and the random effect such as additive genetic were fitted in longevity animal model. The more detailed definition of the statistical models can be found in Guo et al. (2014), Liu et al. (2017), and Zhang et al. $(2019,2021)$. These analyses were implemented based on the average information-restricted maximum likelihood (AI-REML) procedure in DMU software (Madsen et al., 2006).

\section{RESULTS}

\section{Descriptive Statistics}

The descriptive statistics for the 4 BHB traits are presented in Table 1. The BHBp concentration ranged from 0.004 to $4.818 \mathrm{mmol} / \mathrm{L}$, with an average of 1.450 $\mathrm{mmol} / \mathrm{L}$ and a standard deviation of $0.468 \mathrm{mmol} / \mathrm{L}$. The average concentration of BHBp is highest (1.686 $\mathrm{mmol} / \mathrm{L}$ ) in early lactation (5-65 DIM) and lowest (1.361 mmol/L) in later lactation (245-305 DIM). The density distribution of BHB is presented in Figure 1 , in which the differences in BHB concentration across multiple parities are statistically significant $(P<0.01)$. The BHB least squares means decreased from $1.498 \mathrm{mmol} / \mathrm{L}$ (parity 1 ) to $1.396 \mathrm{mmol} / \mathrm{L}$ (parity $3+$ ), but the coefficient of variation $(\mathbf{C V})$ ranged from 30.213 to $34.417 \%$. In addition, the proportion of records with $\mathrm{BHB}$ values within $>1.2$ to $<3.0 \mathrm{mmol} / \mathrm{L}$ (subclinical ketosis) and $\geq 3.0 \mathrm{mmol} / \mathrm{L}$ (clinical ketosis) groups for different lactation stages are shown in 


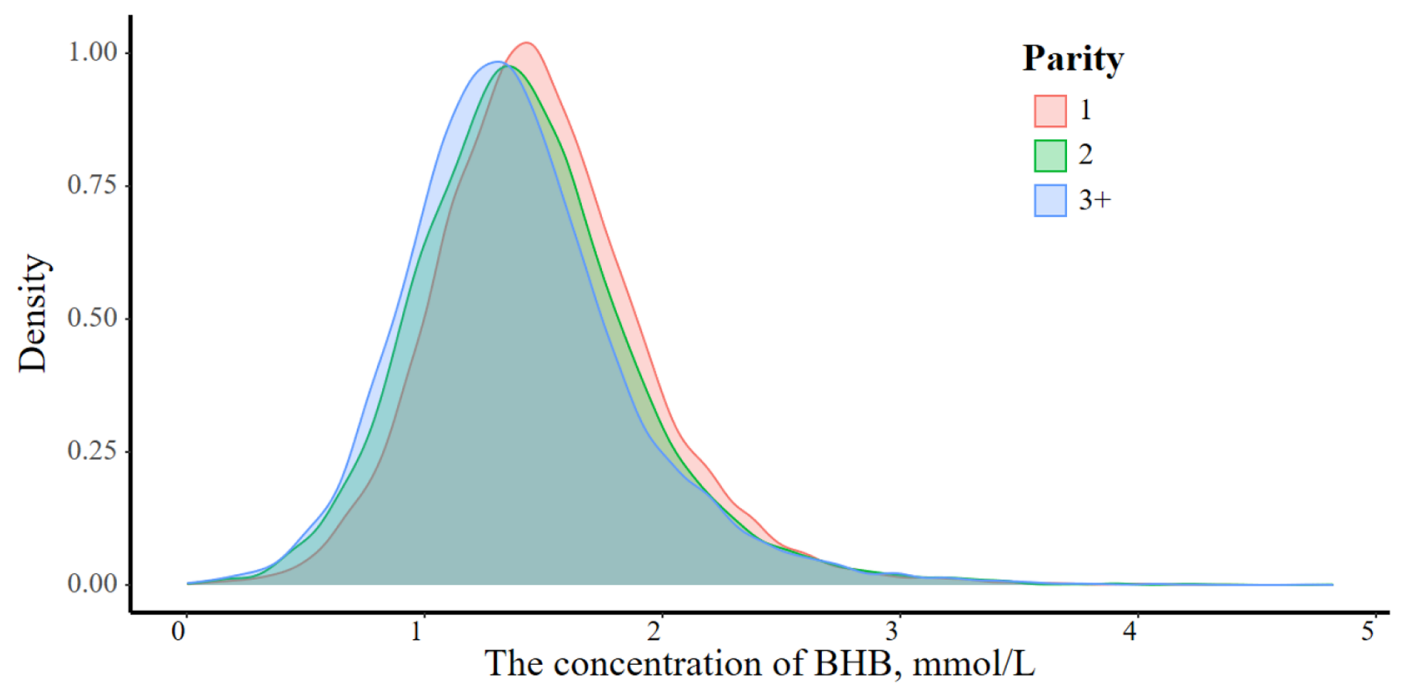

Figure 1. The density distribution of predicted blood BHB concentration (mmol/L) in different parities $(1,2,3+)$ in Holstein cattle.

Figure 2. The frequencies of subclinical and clinical ketosis are highest in the early lactation, and the proportion of healthy individuals gradually increases with the progression of DIM. Compared with BHBp, BHB1, and BHB2, the curve of BHB3 had a faster slope in Figure 2(a). In general, greater BHB levels are associated with higher incidence of ketosis (Benedet et al., 2019).

\section{Genetic Parameter Estimates}

Estimates of variance components, heritability, and repeatability for predicted blood BHB and correlations across multiple parities are presented in Tables 2 and 3 . The heritability estimate based on records from all parities was $0.116 \pm 0.018$, with a repeatability of 0.241 . The heritability of predicted blood BHB was the highest $(0.131 \pm 0.023)$ in the first parity and the lowest $(0.100$ $\pm 0.026)$ in the second parity. We found small differences in the repeatability of predicted blood BHB across parities, ranging from 0.236 (BHB2) to 0.262 (BHB1). Thus, predicted blood BHB traits had low to moderate heritability and repeatability estimates. Meanwhile, we observed high genetic correlations among different pari- ties based on model 2, ranging from 0.788 (BHB2 and BHB3) to 0.911 (BHB1 and BHB3).

The trends of variance components and heritability for BHBp with DIM are shown in Figure 3. From 5 to 305 DIM, the additive genetic variance ranged from 0.011 to 0.097 and the permanent environmental variance ranged from 0.006 to 0.274 . These estimates were greater at the beginning of the lactation, and declined rapidly from 5 to 100 DIM. Over the whole lactation period, the highest $(0.195)$ and lowest $(0.069)$ heritability for BHBp was observed at the beginning and end of lactation, respectively, whereas the average heritability estimate is 0.101 . The BHBp heritability rapidly decreased from calving to $100 \mathrm{DIM}$ as well as the genetic additive effect. The BHBp repeatability ranged from 0.743 to 0.138 , with an average of 0.218 .

Overall, similar genetic parameter trends were observed for BHB across parities. However, there are some differences in certain lactation stages. For instance, BHB1 has the highest heritability at the beginning of lactation, whereas BHB2 has significant fluctuation of heritability estimates at the middle of lactation. The BHB1 and BHB2 have higher repeatability at the end of the lactation compared with BHB3.

Table 1. Descriptive statistics of predicted blood BHB traits in Chinese Holstein cattle ${ }^{1}$

\begin{tabular}{lrccccc}
\hline Trait & $\mathrm{n}$ & No. of cows & Mean $(\mathrm{mmol} / \mathrm{L})$ & $\mathrm{SD}$ & Minimum & Maximum \\
\hline BHBp & 34,338 & 11,609 & 1.450 & 0.468 & 0.004 & 4.818 \\
BHB1 & 15,401 & 6,420 & 1.499 & 0.453 & 0.025 & 4.363 \\
BHB2 & 9,467 & 4,395 & 1.432 & 0.474 & 0.011 & 4.818 \\
BHB3 & 9,470 & 3,925 & 1.390 & 0.478 & 0.004 & 4.711 \\
\hline
\end{tabular}

${ }^{1} \mathrm{n}=$ number of records; BHBp = predicted blood BHB in all parities; BHB1 = predicted blood BHB in first parity; BHB2 = predicted blood $\mathrm{BHB}$ in second parity; BHB3 = predicted blood BHB in parity $3+$. 

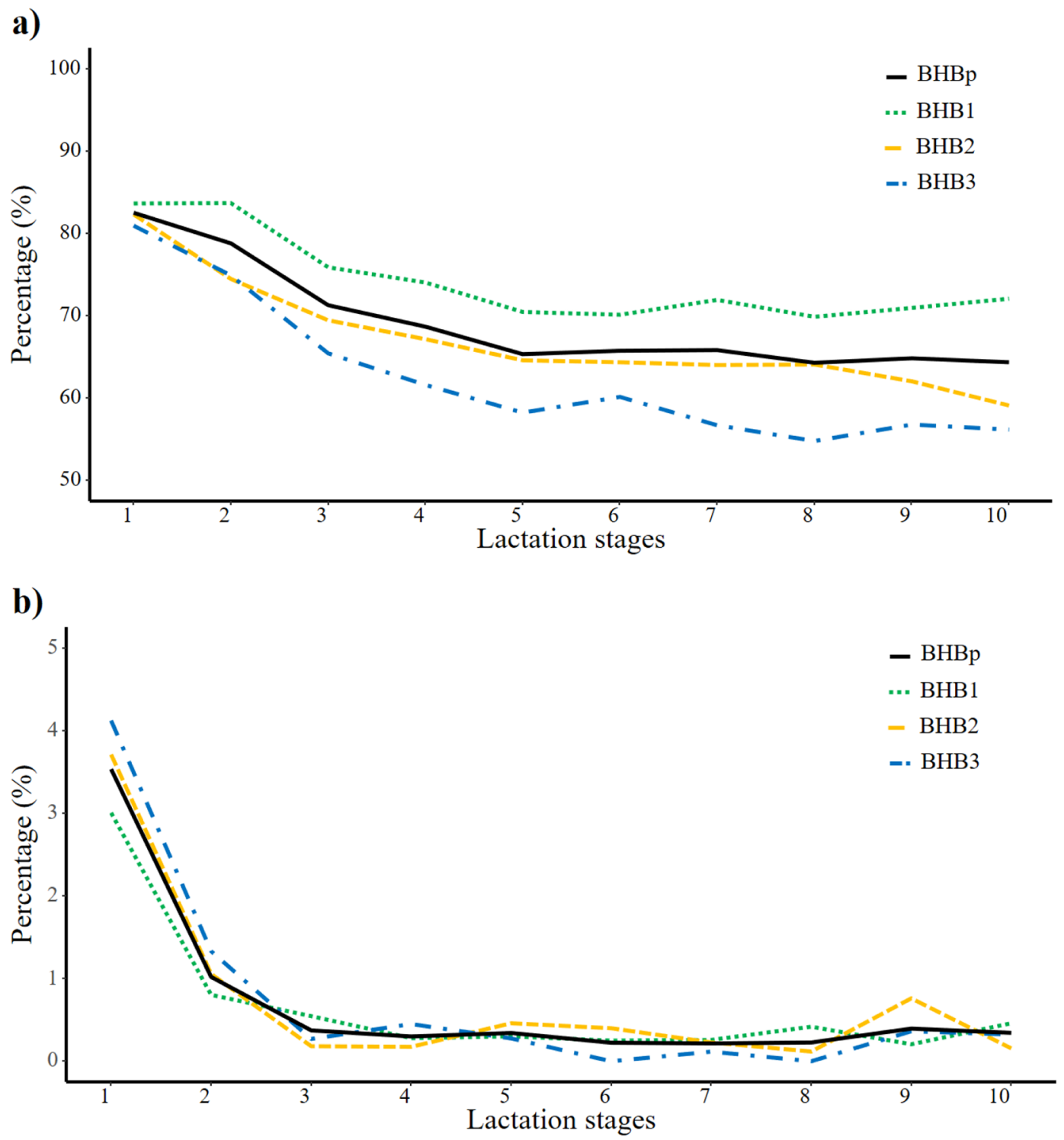

Figure 2. The proportion of predicted blood BHB records within the range of subclinical $(>1.2$ to $<3.0 \mathrm{mmol} / \mathrm{L}$; a) and clinical $(\geq 3.0$ $\mathrm{mmol} / \mathrm{L}$; b) ketosis groups for different lactation stages (30 d per stage) during the period from 5 to $305 \mathrm{~d}$ in all parities (BHBp), parity 1 (BHB1), parity 2 (BHB2), and parity $3+$ (BHB3).

Table 2. Estimates of genetic parameters and variance components for predicted blood BHB in Chinese Holstein cattle $^{1}$

\begin{tabular}{lccccc}
\hline Trait & $\sigma_{a}^{2} \pm \mathrm{SE}$ & $\sigma_{p e}^{2} \pm \mathrm{SE}$ & $\sigma_{e}^{2} \pm \mathrm{SE}$ & $\mathrm{h}^{2} \pm \mathrm{SE}$ & $\mathrm{r}_{\mathrm{e}}$ \\
\hline BHBp & $0.013 \pm 0.002$ & $0.014 \pm 0.002$ & $0.085 \pm 0.007$ & $0.116 \pm 0.018$ & 0.241 \\
BHB1 & $0.014 \pm 0.003$ & $0.014 \pm 0.003$ & $0.079 \pm 0.002$ & $0.131 \pm 0.023$ & 0.262 \\
BHB2 & $0.011 \pm 0.003$ & $0.015 \pm 0.002$ & $0.084 \pm 0.006$ & $0.100 \pm 0.026$ & 0.236 \\
BHB3 & $0.013 \pm 0.003$ & $0.015 \pm 0.003$ & $0.085 \pm 0.003$ & $0.115 \pm 0.025$ & 0.248 \\
\hline
\end{tabular}

${ }^{1} \sigma_{a}^{2}=$ additive genetic variance; $\sigma_{p e}^{2}=$ permanent environmental variance; $\sigma_{e}^{2}=$ residual variance; $\mathrm{r}_{\mathrm{e}}=$ repeatability; $\mathrm{BHBp}=$ predicted blood $\mathrm{BHB}$ in all parities; $\mathrm{BHB} 1=$ predicted blood $\mathrm{BHB}$ in parity 1 ; $\mathrm{BHB} 2=$ predicted blood BHB in parity 2; BHB3 = predicted blood BHB in parity $3+$. 
Table 3. The genetic correlation (above the diagonal) and its SE (below the diagonal) for predicted blood BHB during different parities in Chinese Holstein cattle ${ }^{1}$

\begin{tabular}{lccc}
\hline Trait & BHB1 & BHB2 & BHB3 \\
\hline BHB1 & - & 0.788 & 0.911 \\
BHB2 & 0.144 & - & 0.930 \\
BHB3 & 0.148 & 0.173 & - \\
\hline
\end{tabular}

$\overline{{ }^{1} \mathrm{BHB} 1}=$ predicted blood $\mathrm{BHB}$ in parity $1 ; \mathrm{BHB} 2=$ predicted blood BHB in parity 2 ; BHB3 = predicted blood $\mathrm{BHB}$ in parity $3+$.

\section{Genetic Correlations for BHB with Reproduction and Longevity Traits}

Genetic correlations for the BHBp with reproduction and longevity traits during the whole (5-305 DIM), early (5-65 DIM), and late (245-305 DIM) lactation are presented in Tables 4 and 5. For the entire lactation, the genetic correlations between reproduction traits and BHBp ranged from $-0.084 \pm 0.017$ (AFS) to $0.141 \pm 0.032$ (AFC). There were low and positive genetic correlations for BHBp with AFC (0.141 \pm $0.032)$, IFLC2 (0.138 \pm 0.018), and IFLH $(0.104 \pm$ 0.026). The PL is negatively genetically correlated
$(-0.126 \pm 0.021)$ with BHBp, whereas the other estimates are small or not different from zero. Otherwise, the genetic correlations are similar in early (5-65 DIM) and late lactations (245-305 DIM) compared with the whole lactation, especially for longevity traits. Supplemental Tables S3 (https://figshare.com/articles/ dataset/Supplemental_Table_S3_docx/18133736), S4 (https://figshare.com/articles/dataset/Supplemental _Table_S4_docx/18133757), and S5 (https://figshare .com/articles/dataset/Supplemental_Table_S5_docx/ 18133742) show the different relationship for BHB measured in different parities with reproduction and longevity traits. Most of the genetic correlations are negligible, except for AFC, IFLC2, IFLH, and PL.

\section{DISCUSSION}

Intensive selection for production traits over the past 50 years has led cows to adjust their metabolism to distribute more nutrients and energy toward milk synthesis (Rauw et al., 1998; Miglior et al., 2017). Thus, high-producing cows rely more on body reserves to support milking, and most of them suffer from metabolic a)

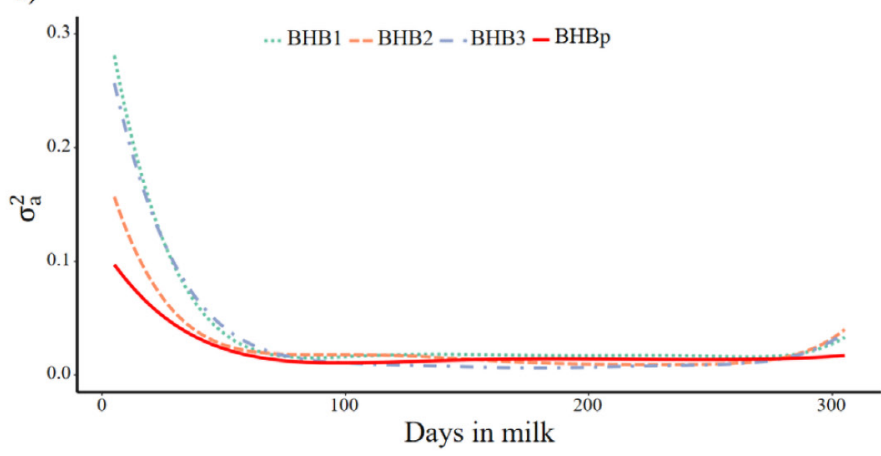

b)

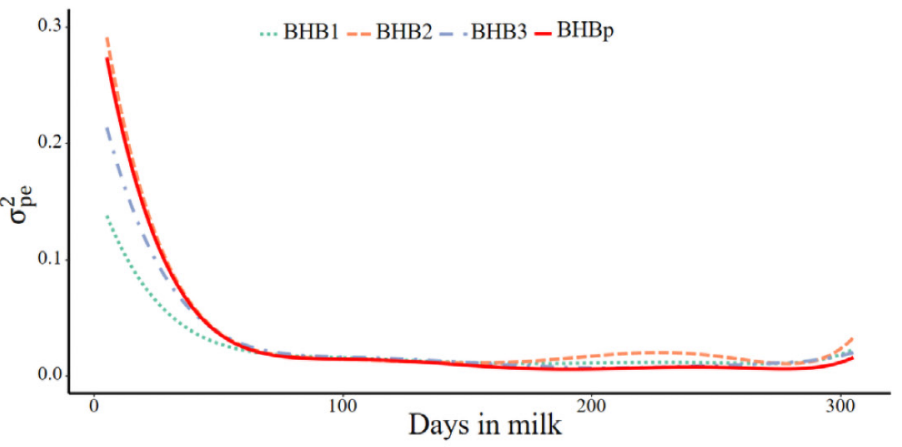

c)

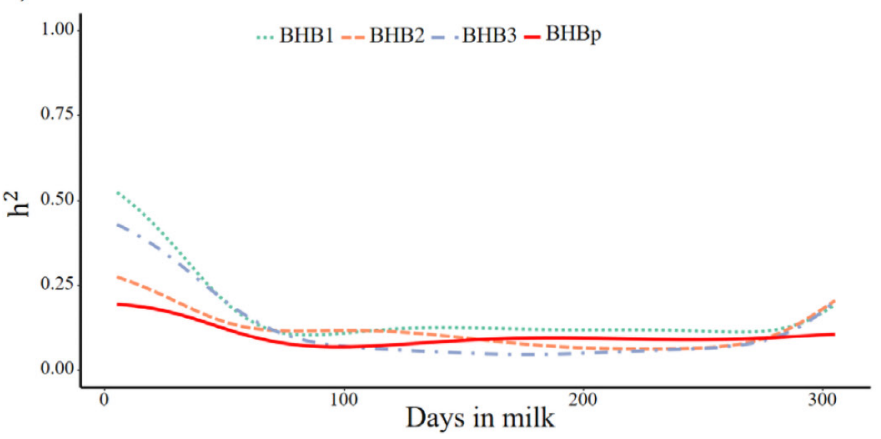

d)

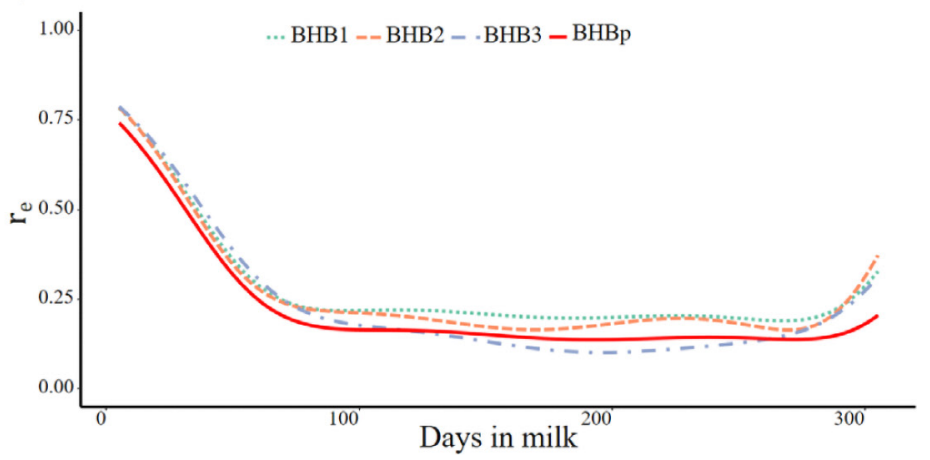

Figure 3. The trends in genetic variance components $\left(\sigma_{a}^{2}=\right.$ additive genetic variance; $\sigma_{p e}^{2}=$ permanent environmental variance; $\mathrm{r}_{\mathrm{e}}=$ repeatability) for predicted blood $\mathrm{BHB}(\mathrm{BHBp}=$ predicted blood $\mathrm{BHB}$ in all parities; $\mathrm{BHB} 1=$ predicted blood $\mathrm{BHB}$ in parity 1 ; BHB2 = predicted blood BHB in parity 2; BHB3 = predicted blood BHB in parity $3+$ ) with the increase in DIM based on a random regression test-day model in Chinese Holstein cattle. 
Table 4. The genetic correlations between predicted blood BHB and reproduction traits in Chinese Holstein cattle based on bivariate animal models ${ }^{1}$

\begin{tabular}{lcrrr}
\hline Trait & $\mathrm{h}^{2} \pm \mathrm{SE}$ & BHBp $(5-305 \mathrm{~d})$ & BHBp $(5-65 \mathrm{~d})$ & \multicolumn{1}{c}{ BHBp $(245-305 \mathrm{~d})$} \\
\hline AFC & $0.068 \pm 0.005$ & $0.141 \pm 0.032$ & $0.157 \pm 0.019$ & $0.041 \pm 0.009$ \\
AFS & $0.266 \pm 0.013$ & $-0.084 \pm 0.017$ & $-0.063 \pm 0.003$ & $-0.004 \pm 0.002$ \\
ICF1 & $0.034 \pm 0.004$ & $-0.069 \pm 0.003$ & $-0.078 \pm 0.006$ & $-0.002 \pm 0.001$ \\
ICF2 & $0.016 \pm 0.002$ & $-0.089 \pm 0.011$ & $-0.071 \pm 0.005$ & $-0.064 \pm 0.012$ \\
IFLC1 & $0.021 \pm 0.005$ & $0.090 \pm 0.004$ & $-0.068 \pm 0.011$ & $0.063 \pm 0.014$ \\
IFLC2 & $0.013 \pm 0.002$ & $0.138 \pm 0.018$ & $0.044 \pm 0.002$ & $0.121 \pm 0.032$ \\
IFLH & $0.008 \pm 0.001$ & $0.104 \pm 0.026$ & $0.111 \pm 0.006$ & $0.078 \pm 0.013$ \\
\hline
\end{tabular}

${ }^{1}$ BHBp $(5-305 \mathrm{~d})=$ predicted blood BHB in all parities during the period of 5 to 305 DIM; BHBp (5-65 d) = predicted blood BHB in all parities during the period of 5 to 65 DIM; BHBp $(245-305 \mathrm{~d})=$ predicted blood BHB in all parities during the period of 245 to 305 DIM; AFC = age at first calving (d); AFS = age at first insemination (d); ICF1 = interval from calving to first insemination in first-parity cows (d); ICF2 = interval from calving to first insemination in multiparous cows (d); IFLC1 = interval from first to last insemination of first-parity cows (d); IFLC2 = interval from first to last insemination of multiparous cows (d); IFLH = interval from first to last insemination of heifers (d).

disorders in the transition period (Grummer, 1995; Lean et al., 2013), which tend to result in increased ketosis incidence and decline in reproductive performance and longevity (Lucy, 2001; De Vries and Marcondes, 2020). Therefore, we estimated genetic parameters for predicted blood BHB using linear repeatability, multiple-trait, and random regression test-day models, and calculated genetic correlations for BHB indicators with reproductive and longevity traits in Chinese Holstein cattle.

\section{Descriptive Statistics}

The measures of predicted blood BHB in this study are different from traditional test results such as the enzymatic kinetic method (0.19-4.42 mmol/L; Oikonomou et al., 2008), in which few cows tend to have measures lower than zero. This may be associated with the low BHB content in milk (Benedet et al., 2019). A similar finding was also reported in Norwegian Red cattle, in which predicted blood BHB ranged from -4.05 to $6.32 \mathrm{mmol} / \mathrm{L}$ with a mean of $1.19 \mathrm{mmol} / \mathrm{L}$ (Belay et al., 2017). The average concentrations measured with continuous flow analyzer in Canadian Holstein cattle and spectrophotometric kinetic method in Greek Holstein cattle were 1.14 and $0.829 \mathrm{mmol} / \mathrm{L}$, respectively (Denis-Robichaud et al., 2014; Tsiamadis et al., 2016). The average value $(1.45 \mathrm{mmol} / \mathrm{L})$ of Chinese Holstein cattle presented in this research is higher compared with these reported results. Such differences in blood BHB among populations might be due to differences in breed, production level, physiological stage, feeding management, and detection device (e.g., Foss or Bentley). In this context, it has been reported that the incidence of hyperketonemia differs across parity, lactation, and season (van der Drift et al., 2012b). In addition, the incidences of subclinical and clinical ketosis are higher in the early lactation, and their sum is over $80 \%$. Cows with high milk yield usually have higher incidence of ketosis. In this study, the average daily milk yield is $35 \pm 9 \mathrm{~kg}$. Inaccurate BHB predictions could be another reason causing error classification at

Table 5. The genetic correlations between predicted blood BHB and longevity traits in Chinese Holstein cattle based on bivariate animal models ${ }^{1}$

\begin{tabular}{lcccc}
\hline Trait & $\mathrm{h}^{2} \pm \mathrm{SE}$ & BHBp $(5-305 \mathrm{~d})$ & BHBp $(5-65 \mathrm{~d})$ & BHBp $(245-305 \mathrm{~d})$ \\
\hline PL & $0.034 \pm 0.005$ & $-0.126 \pm 0.011$ & $-0.168 \pm 0.019$ & $-0.134 \pm 0.009$ \\
LS1 & $0.076 \pm 0.008$ & $-0.035 \pm 0.008$ & $-0.039 \pm 0.002$ & $-0.055 \pm 0.006$ \\
LS2 & $0.054 \pm 0.007$ & $-0.079 \pm 0.005$ & $-0.067 \pm 0.007$ & $-0.031 \pm 0.006$ \\
LS3 & $0.048 \pm 0.004$ & $-0.080 \pm 0.009$ & $-0.083 \pm 0.010$ & $-0.091 \pm 0.019$ \\
LS4 & $0.046 \pm 0.003$ & $-0.083 \pm 0.008$ & $-0.056 \pm 0.007$ & $-0.101 \pm 0.020$ \\
LS5 & $0.048 \pm 0.006$ & $-0.059 \pm 0.006$ & $-0.014 \pm 0.004$ & $-0.061 \pm 0.012$
\end{tabular}

${ }^{1}$ BHBp $(5-305 \mathrm{~d})=$ predicted blood BHB in all parities during the period of 5 to 305 DIM; BHBp $(5-65 \mathrm{~d})=$ predicted blood BHB in all parities during the period of 5 to 65 DIM; BHBp (245-305 d) = predicted blood BHB in all parities during the period of 245 to 305 DIM; LS1 = first calving to the end of the first parity (d); LS2 = first calving to the end of the second parity (d); LS3 = first calving to the end of the third parity (d); LS4 = first calving to the end of the fourth parity (d); LS5 = first calving to the end of the fifth parity (d); $\mathrm{PL}=$ days from the first calving to culling or death (d). 
different levels, which means the predicted blood BHB is more suitable to present a relative value between different cows instead of the exact level.

The trend in blood BHB along with DIM in Chinese Holstein cows is consistent with other studies in the literature where the peak $\mathrm{BHB}$ concentration is observed during the first 3 to 4 wk after calving (Oetzel, 2007; Koeck et al., 2014; Belay et al., 2017). Due to the variation of physiological status in a cow's lifetime, previous reports indicated that first-parity cows have lower odds of ketosis compared with cows in parity 3 to 7 (e.g., Berge and Vertenten, 2014), which is contrary to the reduction in blood BHB and lower incidence of subclinical ketosis for higher parities in this study. The proportion curve of different parity in Figure 2 revealed that older cows respond and regulate more quickly to mitigate or eliminate ketosis symptoms.

\section{Heritability Estimates}

The BHB heritability estimate in this study was low to moderate based on a linear repeatability model, ranging from 0.100 to 0.131 , as reported in previous studies (van der Drift et al., 2012b; Tsiamadis et al., 2016), and higher than the values $(0.01-0.10)$ for ketosis and hyperketonemia evaluated on a categorical scale (Van Dorp et al., 1998; Kadarmideen et al., 2000; Koeck et al., 2012; Häggman et al., 2019). It seems that continuous phenotypes, such as blood BHB concentration, are better indicators of ketosis susceptibility to be used in breeding programs. The heritability estimates were lower when compared with previous studies based on milk BHB in Korean Holstein cattle, in which the BHB heritability estimates ranged from 0.09 to 0.19 (Ranaraja et al., 2018). The population, data set structure, and statistical models used are likely the main reasons for the differences observed in the aforementioned studies. Although low heritability estimates can indicate slower genetic progress, higher estimates may be observed by using larger (and more representative) data sets obtained through other techniques such as FT-MIR spectra of milk or alternative ketosis indicators. The high and positive genetic correlation between BHB indicators across parities indicate that genetic and genomic selection for BHB1 is also expected to reduce the incidence of ketosis in later parities. The moderate repeatability estimates $(0.236-0.262)$ observed indicate that these traits are greatly affected by the environment and repeated records are essential to improve the accuracy of breeding values.

The daily genetic heritability for BHBp are similar to those reported by Oikonomou et al. (2008) in Holstein cows. The heritability of predicted blood BHB in
Norwegian Red cattle had an upward trend from 11 to $120 \mathrm{~d}$ after calving (Belay et al., 2017). However, daily genetic parameters for BHB1, BHB2, and BHB3 were not found in the literature. Therefore, no direct comparisons were made. Lee et al. (2016) reported similar results for milk BHB, in which the trend of the daily additive genetic variance in first parity was similar. In this study, the third-order Legendre orthogonal polynomials were fitted because higher orders caused overfitting.

The higher heritability estimates in the early lactation stage (first $100 \mathrm{~d}$ after calving) may be associated with the greater variability and prevalence of metabolic challenges faced by high-producing cows during this transition period. Dairy cows need to mobilize their reserves to cope with NEB or other disturbances during the transition period (Drackley, 1999; Sundrum, 2015). Cows with higher ketosis resilience better cope with the metabolic stress at the beginning of the lactation period. Thus, genetically selecting for reduced BHB in the early lactation stage is promising. The aim of fitting random regression is to model the deviations around the phenotypic trajectories of BHB concentration. Compared with the repeatability model, the Legendre orthogonal polynomial was found to be the most adequate way of modeling changes in the trait variance over time, which considers the relationship among the measurements over time (Jamrozik et al., 1997; Oliveira et al., 2019). This approach is more consistent with the actual physiological characteristics of BHB in cows. The average daily heritability $(0.101)$ is close to the repeatability model estimate (0.116) in BHBp. We compared the repeatability model and random regression model by calculating the Spearman correlation of the top 300-bull EBVs for the 4 BHB traits. The high Spearman correlations $(0.941-0.985)$ indicate that the models are similar.

\section{Genetic Correlations for BHB with Reproduction and Longevity Traits}

In this study, low direct genetic correlations were observed between BHB and the 7 reproduction traits evaluated. During the period from 5 to 305 DIM, the negative relationships between BHBp with AFS $(-0.084 \pm 0.017)$, ICF1 $(-0.069 \pm 0.003)$, and ICF2 $(-0.089 \pm 0.011)$ indicate that individuals with better reproductive performance (early insemination and less time for involution of uterus) may have slightly higher BHB concentrations in the blood. This might be due to greater energy requirements to maintain high reproductive performance, whereas excessive magnitude or rate of mobilization of fat reserves will cause higher 
concentration of BHB in blood. In Finnish dairy cattle, a genetic correlation of $-0.17 \pm 0.042$ between BHB concentration and interval from calving to the first heat (similar to ICF) was also observed (Häggman et al., 2019), which corroborates with our findings. We found positive genetic correlations between BHBp and IFL for heifers $(0.104 \pm 0.026)$ and multiparous cows $(0.138 \pm$ 0.018), whereas the genetic correlation between BHBp and AFC was $0.141 \pm 0.032$. These results indicate that animals with higher BHB concentration in the blood often need to be inseminated more times to get a successful pregnancy. The blood BHB concentration of nonpregnant Canadian Holstein cows after the first AI was higher than that of pregnant individuals between 3 wk before and 9 wk after calving (Walsh et al., 2007). This indicate that high concentration of blood BHB will increase the risk of pregnancy. Impaired reproduction was related to the brain's regulation of reproduction and metabolism (Rodriguez-Martinez, 2010), because the NEB hinders communication along the hypothalamic-pituitary-ovarian axis and ultimately influences the recovery of reproductive function (Butler and Smith, 1989).

During the period from 5 to 305 DIM, low genetic correlations were observed between longevity indicators and BHBp, with the highest correlation with PL $(-0.126 \pm 0.011)$ and small genetic association with the other indicators. In general, PL is more representative than other longevity traits; the negative trend of the low genetic correlation still indicated that individuals may be culled early due to the higher concentration of blood BHB. In addition to the lower milk production, other traits such as mastitis, foot and leg injury, fertility performance, and other metabolic diseases also affect the individual life span (De Vries and Marcondes, 2020). Thus, culling rate is influenced by the combination of various factors and ketosis accounts for only a small proportion of culling reasons.

The genetic correlations for BHBp with some reproductive (AFC, ICF1, IFLH) and longevity (PL) traits have slight increase at the beginning of lactation (5-65 d) compared with the whole lactation (5-305 d) results, which indicates that selecting animals with lower BHB concentration in early lactation leads to greater genetic progress in other traits. In addition, Supplemental Tables S3, S4, and S5 revealed that the 13 traits have different genetic correlations with BHB1 to BHB3 in the whole, early, and late lactation stage. Even though the estimates are small, these findings indicated that the genetic correlations change with age and lactation stage. The data size and statistical models affect the genetic correlation estimates. This result should be interpreted with caution, while providing a great reference for reproductive and longevity study in the future.
Therefore, additional studies should be performed to validate these results in larger populations.

\section{Perspectives}

With the help of an automated detection system such as FT-MIR spectroscopy, predicted blood BHB records from a large population can be obtained and used for genetic (and genomic) selection in dairy cattle breeding programs. As predicted blood BHB in early lactation has higher heritability but there are low genetic correlations for predicted blood BHB with reproductive and longevity traits, we expect that selection of the predicted blood BHB can not only provide a choice for selecting for ketosis resistance in early lactation but also be used as a complementary indicator trait in the selection index of Chinese Holstein cattle in the future. Based on the above results, these genetic correlations and heritability estimates will be validated based on clinical and subclinical ketosis records in future studies also incorporating genomic information. Furthermore, genomic analyses of predicted blood BHB will be conducted to identify genomic markers associated with ketosis resistance in Chinese Holstein cattle.

\section{CONCLUSIONS}

Predicted blood BHB traits are low to moderately heritable and repeatable $(0.100-0.131 ; 0.236-0.262$, respectively), with genetic correlations across parities ranging from 0.788 to 0.911 . This indicates that genetic progress for reduced BHB concentration can be achieved through direct selection and selection for BHB1 (first parity) is expected to indirectly reduce $\mathrm{BHB}$ in higher lactations. The $4 \mathrm{BHB}$ traits (BHBp, BHB1, BHB2, and BHB3) evaluated have similar genetic parameters throughout lactation and high heritability in early lactation, which means that selecting low BHB concentration after calving is more effective. The 4 BHB traits have low direct genetic correlations with selected reproduction and longevity traits and they change with parity and lactation stage. During the period from 5 to 65 DIM, a higher BHBp present in blood was genetically associated with older age at first calving (0.157 \pm 0.019$)$, longer IFLH $(0.111 \pm 0.006)$, and shorter production life $(-0.168 \pm 0.019)$. As more predicted BHB data accumulate, additional studies will be performed.

\section{ACKNOWLEDGMENTS}

This study was supported by the China Agriculture Research System of the Ministry of Finance and the Ministry of Agriculture and Rural Affairs (Beijing, 
China). We also thank the Dairy Association of China (Beijing, China) for providing the pedigree datasets. The authors have not stated any conflicts of interest.

\section{REFERENCES}

Andersson, L., A. H. Gustafsson, and U. Emanuelson. 1991. Effect of hyperketonemia and feeding on fertility in dairy cows. Theriogenology 36:521-536. https://doi.org/10.1016/0093-691X(91)90392-Q.

Belay, T. K., M. Svendsen, Z. M. Kowalski, and T. Ådnøy. 2017. Genetic parameters of blood $\beta$-hydroxybutyrate predicted from milk infrared spectra and clinical ketosis, and their associations with milk production traits in Norwegian Red cows. J. Dairy Sci 100:6298-6311. https://doi.org/10.3168/jds.2016-12458.

Benedet, A., C. L. Manuelian, A. Zidi, M. Penasa, and M. De. Marchi. 2019. Invited review: $\beta$-hydroxybutyrate concentration in blood and milk and its associations with cow performance. Animal 13:1676-1689. https://doi.org/10.1017/S175173111900034X.

Berge, A. C., and G. Vertenten. 2014. A field study to determine the prevalence, dairy herd management systems, and fresh cow clinical conditions associated with ketosis in western European dairy herds. J. Dairy Sci. 97:2145-2154. https://doi.org/10.3168/jds 2013-7163.

Butler, W. R., and R. D. Smith. 1989. Interrelationships between energy balance and postpartum reproductive function in dairy cattle. J. Dairy Sci. 72:767-783. https://doi.org/10.3168/jds.S0022 -0302(89)79169-4.

Cobby, J. M., and Y. L. P. Le Du. 1978. On fitting curves to lactation data. Anim. Sci. 26:127-133. https://doi.org/10.1017/ S0003356100039532.

De Vries, A., and M. Marcondes. 2020. Review: Overview of factors affecting productive lifespan of dairy cows. Animal 14(Suppl. 1):s155-s164. https://doi.org/10.1017/S1751731119003264.

Denis-Robichaud, J., J. Dubuc, D. Lefebvre, and L. DesCôteaux. 2014. Accuracy of milk ketone bodies from flow-injection analysis for the diagnosis of hyperketonemia in dairy cows. J. Dairy Sci. 97:33643370. https://doi.org/10.3168/jds.2013-6744.

Dobson, H., R. F. Smith, M. D. Royal, C. H. Knight, and I. M. Sheldon. 2007. The high-producing dairy cow and its reproductive performance. Reprod. Domest. Anim. 42(Suppl. 2):17-23. https://doi .org/10.1111/j.1439-0531.2007.00906.x.

Drackley, J. K. 1999. ADSA Foundation Scholar Award. Biology of dairy cows during the transition period: The final frontier? J. Dairy Sci. 82:2259-2273. https://doi.org/10.3168/jds.S0022 $-0302(99) 75474-3$

Duffield, T. F., K. D. Lissemore, B. W. McBride, and K. E. Leslie. 2009. Impact of hyperketonemia in early lactation dairy cows on health and production. J. Dairy Sci. 92:571-580. https://doi.org/ 10.3168/jds.2008-1507.

Esposito, G., P. C. Irons, E. C. Webb, and A. Chapwanya. 2014. Interactions between negative energy balance, metabolic diseases, uterine health and immune response in transition dairy cows. Anim. Reprod. Sci. 144:60-71. https://doi.org/10.1016/j.anireprosci.2013 .11 .007 .

Geweke, J. F. 1991. Evaluating the accuracy of sampling-based approaches to the calculation of posterior moments. Staff Report (Federal Reserve Bank of Minneapolis. Research Department). 4:169-193. https://doi.org/10.21034/sr.148.

Grelet, C., C. Bastin, M. Gelé, J.-B. Davière, M. Johan, A. Werner, R. Reding, J. A. Fernandez Pierna, F. G. Colinet, P. Dardenne, N. Gengler, H. Soyeurt, and F. Dehareng. 2016. Development of Fourier transform mid-infrared calibrations to predict acetone, $\beta$-hydroxybutyrate, and citrate contents in bovine milk through a European dairy network. J. Dairy Sci. 99:4816-4825. https://doi .org/10.3168/jds.2015-10477.

Grummer, R. R. 1995. Impact of changes in organic nutrient metabolism on feeding the transition dairy cow. J. Anim. Sci. 73:28202833. https://doi.org/10.2527/1995.7392820x.
Guo, G., X. Guo, Y. Wang, X. Zhang, S. Zhang, X. Li, L. Liu, W. Shi, T. Usman, X. Wang, L. Du, and Q. Zhang. 2014. Estimation of genetic parameters of fertility traits in Chinese Holstein cattle. Can. J. Anim. Sci. 94:281-285. https://doi.org/10.4141/cjas2013-113.

Häggman, J., J. M. Christensen, E. A. Mäntysaari, and J. Juga. 2019. Genetic parameters for endocrine and traditional fertility traits, hyperketonemia and milk yield in dairy cattle. Animal 13:248-255. https://doi.org/10.1017/S1751731118001386.

Hammon, D. S., I. M. Evjen, T. R. Dhiman, J. P. Goff, and J. L. Walters. 2006. Neutrophil function and energy status in Holstein cows with uterine health disorders. Vet. Immunol. Immunopathol. 113:21-29. https://doi.org/10.1016/j.vetimm.2006.03.022.

Herdt, T. H. 2000. Ruminant adaptation to negative energy balance: Influences on the etiology of ketosis and fatty liver. Vet. Clin. North Am. Food Anim. Pract. 16:215-230. https://doi.org/10 .1016/S0749-0720(15)30102-X.

Heuer, C., H. J. Luinge, E. T. G. Lutz, Y. H. Schukken, J. H. van der Maas, H. Wilmink, and J. P. T. M. Noordhuizen. 2001. Determination of acetone in cow milk by Fourier transform infrared spectroscopy for the detection of subclinical ketosis. J. Dairy Sci. 84:575-582. https://doi.org/10.3168/jds.S0022-0302(01)74510-9.

Jamrozik, J. L., R. Schaeffer, and J. C. M. Dekkers. 1997. Genetic evaluation of dairy cattle using test day yields and random regression model. J. Dairy Sci. 80:1217-1226. https://doi.org/10.3168/ jds.S0022-0302(97)76050-8.

Kadarmideen, H. N., R. Thompson, and G. Simm. 2000. Linear and threshold model genetic parameters for disease, fertility and milk production in dairy cattle. Anim. Sci. 71:411-419. https://doi.org/ 10.1017/S1357729800055338.

Kirkpatrick, M., D. Lofsvold, and M. Bulmer. 1990. Analysis of the inheritance, selection and evolution of growth trajectories. Genetics 124:979-993. https://doi.org/10.1093/genetics/124.4.979.

Koeck, A., J. Jamrozik, G. J. Kistemaker, F. S. Schenkel, R. K. Moore, D. M. Lefebvre, D. F. Kelton, and F. Miglior. 2016. Genetic and phenotypic associations of milk $\beta$-hydroxybutyrate with ketosis in Canadian Holsteins. Can. J. Anim. Sci. 96:302-305.

Koeck, A., J. Jamrozik, F. S. Schenkel, R. K. Moore, D. M. Lefebvre, D. F. Kelton, and F. Miglior. 2014. Genetic analysis of milk $\beta$-hydroxybutyrate and its association with fat-to-protein ratio, body condition score, clinical ketosis, and displaced abomasum in early first lactation of Canadian Holsteins. J. Dairy Sci. 97:72867292. https://doi.org/10.3168/jds.2014-8405.

Koeck, A., F. Miglior, D. F. Kelton, and F. S. Schenkel. 2012. Health recording in Canadian Holsteins: Data and genetic parameters. J. Dairy Sci. 95:4099-4108. https://doi.org/10.3168/jds.2011-5127.

Lean, I. J., R. Van Saun, and P. J. Degaris. 2013. Energy and protein nutrition management of transition dairy cows. Vet. Clin. North Am. Food Anim. Pract. 29:337-366. https://doi.org/10.1016/j .cvfa.2013.03.005.

Lee, S., K. H. Cho, M. Park, T. Chao, S. Kim, and C. Do. 2016. Genetic parameters of milk $\beta$-hydroxybutyric acid and acetone and their genetic association with milk production traits of Holstein cattle. Asian-Australas. J. Anim. Sci. 29:1530-1540. https://doi .org/10.5713/ajas.16.0310.

Leroy, J. L. M. R., T. Vanholder, J. R. Delanghe, G. Opsomer, A. Van Soom, P. E. J. Bols, and A. de Kruif. 2004. Metabolite and ionic composition of follicular fluid from different-sized follicles and their relationship to serum concentrations in dairy cows. Anim. Reprod. Sci. 80:201-211. https://doi.org/10.1016/S0378-4320(03)00173-8.

Liu, A., M. S. Lund, Y. Wang, G. Guo, G. Dong, P. Madsen, and G. Su. 2017. Variance components and correlations of female fertility traits in Chinese Holstein population. J. Anim. Sci. Biotechnol. 8:56. https://doi.org/10.1186/s40104-017-0189-x.

Lucy, M. C. 2001. ADSA Foundation Scholar Award: Reproductive loss in high-producing dairy cattle: Where will it end? J. Dairy Sci. 84:1277-1293. https://doi.org/10.3168/jds.S0022-0302(01)70158 $-0$.

Madsen, P., J. Jensen, R. Labouriau, O. F. Christensen, and G. Sahana. 2014. DMU - A package for analyzing multivariate mixed models in quantitative genetics and genomics. Proc. 10th World 
Congress on Genetics Applied to Livestock Production, Vancouver, CA. Accessed Jan.13, 2021. http://pure.au.dk/portal/files/ 82154310/Paper.pdf.

Mahrt, A., O. Burfeind, and W. Heuwieser. 2015. Evaluation of hyperketonemia risk period and screening protocols for early-lactation dairy cows. J. Dairy Sci. 98:3110-3119. https://doi.org/10.3168/ jds.2014-8910.

McArt, J. A. A., D. V. Nydam, and G. R. Oetzel. 2013b. Dry period and parturient predictors of early lactation hyperketonemia in dairy cattle. J. Dairy Sci. 96:198-209. https://doi.org/10.3168/ jds.2012-5681.

McArt, J. A. A., D. V. Nydam, G. R. Oetzel, T. R. Overton, and P. A. Ospina. 2013a. Elevated non-esterified fatty acids and $\beta$-hydroxybutyrate and their association with transition dairy cow performance. Vet. J. 198:560-570. https://doi.org/10.1016/j.tvjl .2013.08.011

McArt, J. A. A., D. V. Nydam, and M. W. Overton. 2015. Hyperketonemia in early lactation dairy cattle: A deterministic estimate of component and total cost per case. J. Dairy Sci. 98:2043-2054. https://doi.org/10.3168/jds.2014-8740.

McLaren, C. J., K. D. Lissemore, T. F. Duffield, K. E. Leslie, and B. Grexton. 2006. The relationship between herd level disease incidence and a return over feed index in Ontario dairy herds. Can. Vet. J. 47:767-773.

Miglior, F., A. Fleming, F. Malchiodi, L. F. Brito, P. Martin, and C. F. Baes. 2017. A 100-Year Review: Identification and genetic selection of economically important traits in dairy cattle. J. Dairy Sci. 100:10251-10271. https://doi.org/10.3168/jds.2017-12968.

Mostert, P. F., E. A. M. Bokkers, C. E. van Middelaar, H. Hogeveen, and I. J. M. de Boer. 2018. Estimating the economic impact of subclinical ketosis in dairy cattle using a dynamic stochastic simulation model. Animal 12:145-154. https://doi.org/10.1017/ S1751731117001306.

Oetzel, G. R. 2007. Herd-level ketosis - Diagnosis and risk factors. Pages 67-91 in Proc. 40th Annual Conference of American Association of Bovine Practitioners. Accessed Jan. 8, 2021. https: //www.vetmed.wisc.edu/dms/fapm/fapmtools/2nutr/ketosis.pdf.

Oikonomou, G., G. E. Valergakis, G. Arsenos, N. Roubies, and G. Banos. 2008. Genetic profile of body energy and blood metabolic traits across lactation in primiparous Holstein cows. J. Dairy Sci. 91:2814-2822. https://doi.org/10.3168/jds.2007-0965.

Oliveira, H. R., L. F. Brito, D. A. L. Lourenco, F. F. Silva, J. Jamrozik, L. R. Schaeffer, and F. S. Schenkel. 2019. Invited review: Advances and applications of random regression models: From quantitative genetics to genomics. J. Dairy Sci. 102:7664-7683. https://doi.org/10.3168/jds.2019-16265.

Oltenacu, P., and D. Broom. 2010. The impact of genetic selection for increased milk yield on the welfare of dairy cows. Anim. Welf. 19:39-49.

Overton, T. R., J. A. A. McArt, and D. V. Nydam. 2017. A 100-Year Review: Metabolic health indicators and management of dairy cattle. J. Dairy Sci. 100:10398-10417. https://doi.org/10.3168/jds 2017-13054.

Plummer, M., N. Best, K. Cowles, K. Vines, D. Sarkar, and R. Almond. 2016. coda: Output Analysis and Diagnostics for MCMC. R package version 0.19-1. Accessed Jun. 13, 2021. https:/CRAN.R -project.org/package $=$ coda.

Pralle, R. S., K. W. Weigel, and H. M. White. 2018. Predicting blood beta-hydroxybutyrate using milk Fourier transform infrared spectrum, milk composition, and producer-reported variables with multiple linear regression, partial least squares regression, and artificial neural network. J. Dairy Sci. 101:4378-4387. https://doi .org/10.3168/jds.2017-14076.

Pryce, J. E., K. L. Parker Gaddis, A. Koeck, C. Bastin, M. Abdelsayed, N. Gengler, F. Miglior, B. Heringstad, C. Egger-Danner, and K. F. Stock. 2016. Invited review: Opportunities for genetic improvement of metabolic diseases. J. Dairy Sci. 99:6855-6873. https://doi.org/10.3168/jds.2016-10854.

Raboisson, D., M. Mounié, and E. Maigné. 2014. Diseases, reproductive performance, and changes in milk production associated with subclinical ketosis in dairy cows: A meta-analysis and review. J. Dairy Sci. 97:7547-7563. https://doi.org/10.3168/jds.2014-8237.

Ranaraja, U., K. H. Cho, M. N. Park, S. D. Kim, S. H. Lee, and C. H. Do. 2018. Genetic parameter estimation for milk $\beta$-hydroxybutyrate and acetone in early lactation and its association with fat to protein ratio and energy balance in Korean Holstein cattle. AsianAustralas. J. Anim. Sci. 31:798-803. https://doi.org/10.5713/ajas .17 .0443 .

Rauw, W. M., E. Kanis, E. N. Noordhuizen-Stassen, and F. J. Grommers. 1998. Undesirable side effects of selection for high production efficiency in farm animals: A review. Livest. Prod. Sci. 56:1533. https://doi.org/10.1016/S0301-6226(98)00147-X.

Reist, M., D. K. Erdin, D. von Euw, K. M. Tschümperlin, H. Leuenberger, H. M. Hammon, C. Morel, C. Philipona, Y. Zbinden, N Künzi, and J. W. Blum. 2003. Postpartum reproductive function: Association with energy, metabolic and endocrine status in high yielding dairy cows. Theriogenology 59:1707-1723. https://doi .org/10.1016/S0093-691X(02)01238-4.

Rodriguez-Martinez, H. 2010. Resource allocation theory applied to farm animal production. Reprod. Domest. Anim. 45:750. https:// doi.org/10.1111/j.1439-0531.2009.01556.x.

Sheldon, I. M., E. J. Williams, A. N. A. Miller, D. M. Nash, and S. Herath. 2008. Uterine diseases in cattle after parturition. Vet. J. 176:115-121. https://doi.org/10.1016/j.tvjl.2007.12.031.

Stevenson, J. S., and J. H. Britt. 2017. A 100-Year Review: Practical female reproductive management. J. Dairy Sci. 100:10292-10313. https://doi.org/10.3168/jds.2017-12959.

Su, G., M. S. Lund, and D. Sorensen. 2007. Selection for litter size at day five to improve litter size at weaning and piglet survival rate. J. Anim. Sci. 85:1385-1392. https://doi.org/10.2527/jas.2006-631.

Sundrum, A. 2015. Metabolic disorders in the transition period indicate that the dairy cows' ability to adapt is overstressed. Animals (Basel) 5:978-1020. https://doi.org/10.3390/ani5040395.

Suthar, V. S., J. Canelas-Raposo, A. Deniz, and W. Heuwieser. 2013. Prevalence of subclinical ketosis and relationships with postpartum diseases in European dairy cows. J. Dairy Sci. 96:2925-2938. https://doi.org/10.3168/jds.2012-6035.

Tsiamadis, V., G. Banos, N. Panousis, M. Kritsepi-Konstantinou, G. Arsenos, and G. Valergakis. 2016. Genetic parameters of subclinical macromineral disorders and major clinical diseases in postparturient Holstein cows. J. Dairy Sci. 99:8901-8914. https://doi.org/ 10.3168/jds.2015-10789.

van der Drift, S. G. A., R. Jorritsma, J. T. Schonewille, H. M. Knijn, and J. A. Stegeman. 2012a. Routine detection of hyperketonemia in dairy cows using Fourier transform infrared spectroscopy analysis of $\beta$-hydroxybutyrate and acetone in milk in combination with test-day information. J. Dairy Sci. 95:4886-4898. https://doi.org/ 10.3168/jds.2011-4417.

van der Drift, S. G. A., K. J. E. van Hulzen, T. G. Teweldemedhn, R Jorritsma, M. Nielen, and H. C. M. Heuven. 2012b. Genetic and nongenetic variation in plasma and milk $\beta$-hydroxybutyrate and milk acetone concentrations of early-lactation dairy cows. J. Dairy Sci. 95:6781-6787. https://doi.org/10.3168/jds.2012-5640.

Van Dorp, T. E., J. C. Dekkers, S. W. Martin, and J. P. Noordhuizen. 1998. Genetic parameters of health disorders, and relationships with 305-day milk yield and conformation traits of registered Holstein cows. J. Dairy Sci. 81:2264-2270. https://doi.org/10.3168/ jds.S0022-0302(98)75806-0.

Vanholder, T., J. Papen, R. Bemers, G. Vertenten, and A. C. B. Berge. 2015. Risk factors for subclinical and clinical ketosis and association with production parameters in dairy cows in the Netherlands. J. Dairy Sci. 98:880-888. https://doi.org/10.3168/jds.2014-8362.

van Knegsel, A. T. M., S. G. A. van der Drift, M. Horneman, A. P. W. de Roos, B. Kemp, and E. A. M. Graat. 2010. Short communication: Ketone body concentration in milk determined by Fourier transform infrared spectroscopy: Value for the detection of hyperketonemia in dairy cows. J. Dairy Sci. 93:3065-3069. https://doi .org/10.3168/jds.2009-2847.

Walsh, R. B., J. S. Walton, D. F. Kelton, S. J. LeBlanc, K. E. Leslie, and T. F. Duffield. 2007. The effect of subclinical ketosis in early 
lactation on reproductive performance of postpartum dairy cows. J. Dairy Sci. 90:2788-2796. https://doi.org/10.3168/jds.2006-560.

Wilmink, J. B. M. 1987. Adjustment of test-day milk, fat and protein yield for age, season and stage of lactation. Livest. Prod. Sci. 16:335-348. https://doi.org/10.1016/0301-6226(87)90003-0.

Zaalberg, R. M., N. Shetty, L. Janss, and A. J. Buitenhuis. 2019. Genetic analysis of Fourier transform infrared milk spectra in Danish Holstein and Danish Jersey. J. Dairy Sci. 102:503-510. https://doi .org/10.3168/jds.2018-14464.

Zhang, H., A. Liu, Y. Wang, H. Luo, X. Yan, X. Guo, X. Li, L. Liu, and G. Su. 2021. Genetic parameters and genome-wide association studies of eight longevity traits representing either full or partial lifespan in Chinese Holsteins. Front. Genet. 12:634986. https://doi .org/10.3389/fgene.2021.634986.

Zhang, H., Y. Wang, Y. Chang, H. Luo, L. F. Brito, Y. Dong, R. Shi, Y. Wang, G. Dong, and L. Liu. 2019. Mortality-culling rates of dairy calves and replacement heifers and its risk factors in
Holstein cattle. Animals (Basel) 9:730. https://doi.org/10.3390/ ani9100730.

\section{ORCIDS}

W. Lou (ㄴ) https://orcid.org/0000-0002-0150-6068

H. Zhang (๑) https://orcid.org/0000-0002-8050-2494

H. Luo @ https://orcid.org/0000-0001-6211-3834

R. Shi $\odot$ https://orcid.org/0000-0002-0047-1262

X. Guo @ https://orcid.org/0000-0001-7354-1519

Y. Zou ๑ https://orcid.org/0000-0002-1017-2768

L. F. Brito @ https://orcid.org/0000-0002-5819-0922

G. Guo (ํ) https://orcid.org/0000-0001-8677-6325

Y. Wang () https://orcid.org/0000-0003-3629-2802 